\title{
Posterior Fossa Neurenteric Cysts Can Expand Rapidly: Case Report
}

\author{
Francesco A.I. Priamo, B.S., ${ }^{1}$ Elpidio D. Jimenez, M.D., ${ }^{2}$ \\ and Ethan A. Benardete, M.D., Ph.D. ${ }^{1}$
}

Neurenteric cysts are considered congenital lesions that may slowly expand over time. Although more commonly found in the spinal canal, they may be found intracranially, particularly in the posterior fossa. Here, we present an unusual case of a large, rapidly expanding histologically confirmed posterior fossa neurenteric cyst in a 53-year-old woman, who presented with quadriparesis. Computed tomography imaging done $\sim 1.5$ years before admission failed to demonstrate any obvious abnormality; however, the lesion had grown to $4 \mathrm{~cm}$ in maximal dimension at presentation with significant mass effect. The lesion was resected microsurgically using a retrosigmoid approach. The patient improved postoperatively and was neurologically intact at last follow-up. We could find no other documented case of marked, rapid expansion of a neurenteric cyst in the literature. We conclude that, although neurenteric cysts are thought to be congenital, they can undergo rapid expansion even in adults. The mechanism of expansion is unknown but may involve increased secretion, hemorrhage, or inflammation. We discuss the surgical management and review the literature in view of this surprising finding.

KEYWORDS: Neurenteric cyst, posterior fossa tumor, microsurgery

Neurenteric cysts are rare, congenital lesions that can occur anywhere along the neuraxis. ${ }^{1}$ They typically present in children and young adults. When they are recognized, neurenteric cysts are more commonly found in the spinal canal and much less frequently intracranially. ${ }^{2}$ The posterior fossa is the most common intracranial location. ${ }^{3}$ Neurenteric cysts are thought to slowly expand by accumulation of the cyst contents. Here we present an unusual case of a 53-year-old woman who complained of headache and weakness in all four extremities. She was found to have a large posterior fossa neurenteric cyst. A computed tomography (CT) done approximately a year and a half earlier failed to reveal any obvious abnormality. We describe this case, the surgical management, and the histopathology, and discuss this case in view of current theories of neurenteric cysts.

\section{CASE REPORT}

\section{History and Examination}

A 53-year-old woman with a medical history significant for hypertension presented with a 3-day history of headaches and a subjective feeling of weakness in all four extremities, worse in the upper extremities than in the lower extremities. On detailed neurological examination, there were no abnormal findings except for slightly decreased strength in bilateral triceps, hand intrinsic

\footnotetext{
${ }^{1}$ Department of Neurosurgery, SUNY Downstate Medical Center; ${ }^{2}$ Department of Pathology \& Laboratory Medicine, Long Island College Hospital, Brooklyn, New York.

Address for correspondence and reprint requests: Ethan A. Benardete, M.D., Ph.D., Instructor, Department of Neurological Surgery, Thomas Jefferson University, 909 Walnut Street, Philadelphia, PA 19107-5211 (e-mail: ethan.benardete@jefferson.edu).
}

Skull Base Rep 2011;1:115-124. Copyright (C) 2011 by Thieme Medical Publishers, Inc., 333 Seventh Avenue, New York, NY 10001, USA. Tel: +1(212) 584-4662.

Received: March 9, 2011. Accepted: May 2, 2011. Published online: July 21, 2011.

DOI: http://dx.doi.org/10.1055/s-0031-1284206.

ISSN 2157-6971. 
muscles, and hip flexors. Routine laboratory tests, chest $\mathrm{X}$-ray, and electrocardiogram were all normal.

\section{Neuroimaging}

A noncontrast head CT was obtained on admission that demonstrated a large, extra-axial hyperdense mass $(3.9 \times 2.2 \times 3.0 \mathrm{~cm})$ in the posterior fossa with significant mass effect on the pons and medulla (Fig. 1). The patient had undergone a noncontrast head CT scan 17 months earlier when she had complained of frequent headaches. This study was read as normal by the neuroradiologist, although there appears to be a small extraaxial lesion on the right near the medulla upon closer review (Fig. 2, arrow). The dimension of this lesion is $\sim 1.2 \times 0.75 \times 1.0 \mathrm{~cm}$.

Magnetic resonance imaging (MRI) of the brain with and without gadolinium administration was then obtained on this admission (Fig. 3). This study demonstrated that the mass was nonenhancing. The mass itself was hyperintense compared with brain parenchyma on T1-weighted imaging and iso- to hypointense on
T2-weighted imaging suggesting a cyst with highly proteinaceous contents. In addition, the flow voids of the basilar artery and its branches appeared to be stretched over the surface of the cyst with perforators to the brain stem passing through it. The preliminary diagnosis based on these findings was a neurenteric cyst, although other types of cystic lesions such as dermoid cyst or cystic schwannoma were also considered.

\section{Operation}

The patient was taken to the operating room, and a left retrosigmoid approach was performed. The patient was positioned supine with the head turned $\sim 80$ degrees to the right. Somatosensory-evoked potentials, motorevoked potentials, facial nerve-monitoring, and brain stem auditory-evoked responses were obtained. A curvilinear incision was made behind the left ear, extending $\sim 6 \mathrm{~cm}$ behind the postauricular crease. The scalp and suboccipital muscles were elevated and retracted in layers. A $4 \times 4 \mathrm{~cm}$ retrosigmoid craniotomy was performed, and then the sigmoid sinus was skeletonized
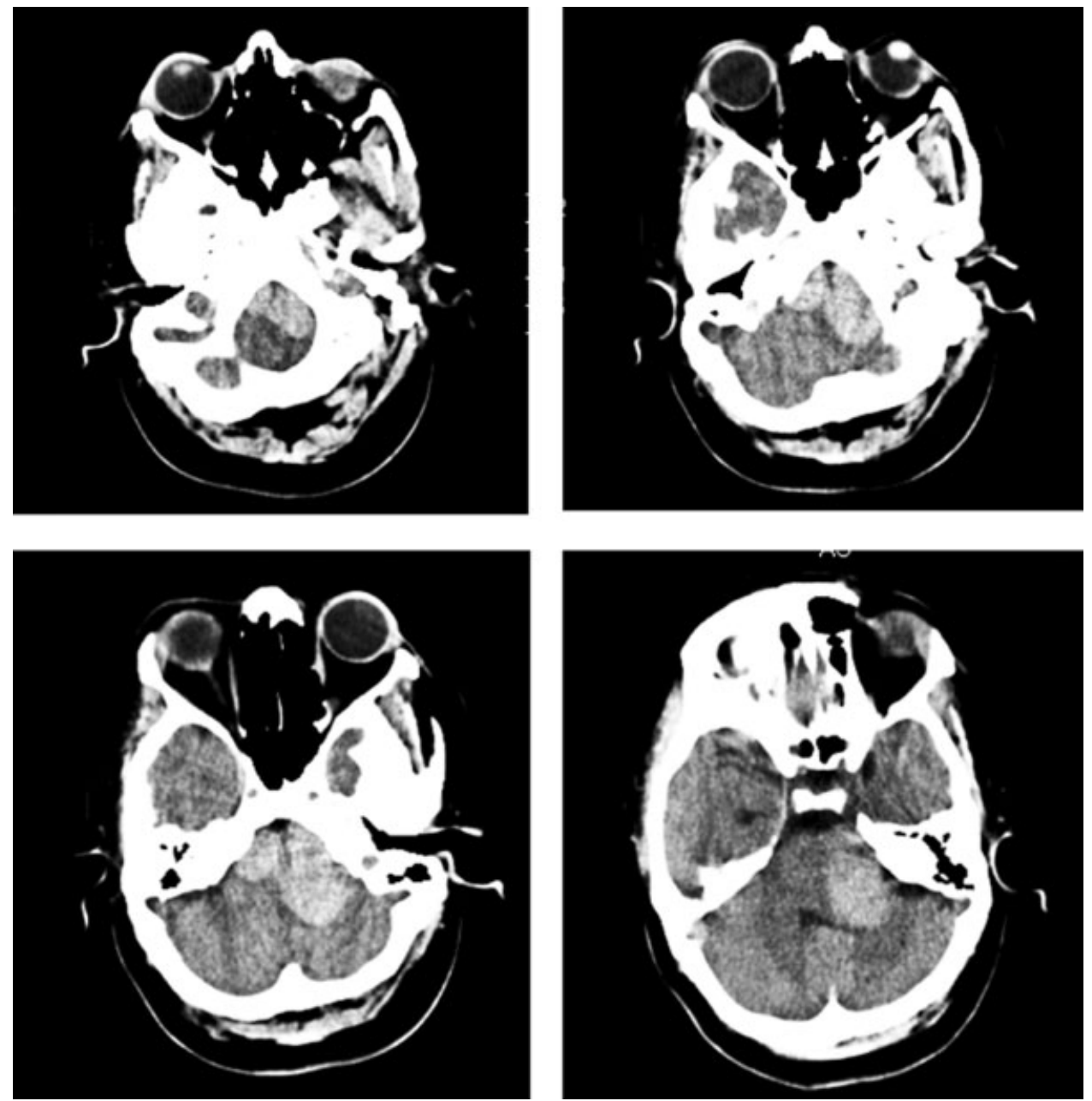

Figure 1 Serial CT scan images done at the time of admission (clockwise from top left) show a hyperdense lesion anterior to the brain stem extending from the foramen magnum up to the tentorium. 

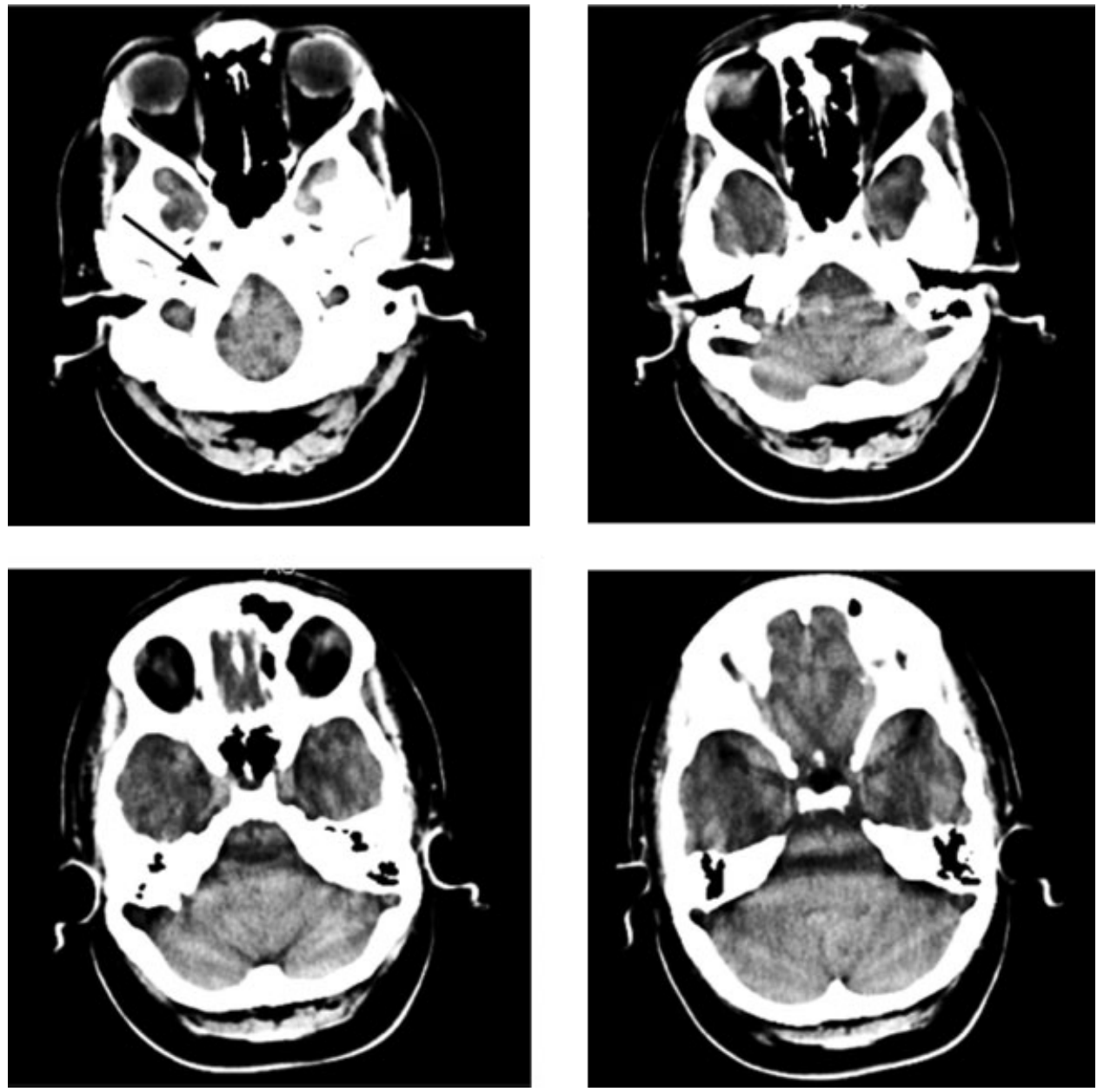

Figure 2 Serial CT scan images (clockwise from top left) obtained 17 months before admission failed to demonstrate significant pathology and were read as normal. A small hyperdensity to the right of the medulla can be seen (arrow).

from the transverse-sigmoid junction down to the jugular bulb to widen the exposure. ${ }^{4}$ The dura was opened such that sigmoid sinus and the transverse sinus were reflected anteriorly and superiorly, respectively, to maximize the exposure along the petrous ridge.

Following release of cerebrospinal fluid (CSF) from the cisterna magna, gentle retraction on the left cerebellar hemisphere brought the lesion into view. The cyst filled the entire cerebellopontine angle from the trigeminal nerve above, down to foramen magnum below. The CN VII/VIII nerve complex was stretched across the top of the cyst (Fig. 4). The translucent cyst walls were filled with tan, viscous contents. Using standard microsurgical techniques, the cyst was opened and evacuated by working through three "corridors": the interval between the trigeminal nerve and the CN VII/ VIII nerve complex, the interval between the CN VII/ VIII nerve complex and the lower cranial nerves, and between the lower cranial nerves and the foramen magnum (Fig. 5). Following removal of the cyst contents, resection of the cyst wall was done sharply where possible. The cyst wall was tightly adherent to the cranial nerves, the surface of the brain stem, and the basilar artery and its branches. A gross total resection of the cyst wall was limited by these structures. Firm deposits on the surface of the pons were sharply resected. There was no evidence of a bony anomaly of the clivus or skull base associated with the cyst. The dura was closed in a watertight fashion. The bone was replaced with cranial fixation plates, and bony defects were filled with hydroxyapatite-based bone substitute. The suboccipital muscles and scalp were closed in a standard fashion. Intravenous steroids, which were started prior surgery, were gradually tapered off.

\section{Histopathological Findings and Postoperative Course}

Multiple microscopic sections of the cyst wall revealed pseudostratified, ciliated epithelium confirming the diagnosis of neurenteric cyst (Fig. 6). In some areas, the cyst wall demonstrated marked squamous metaplasia. The cyst wall showed evidence of recent and old hemorrhage (fresh blood and hemosiderin-laden 

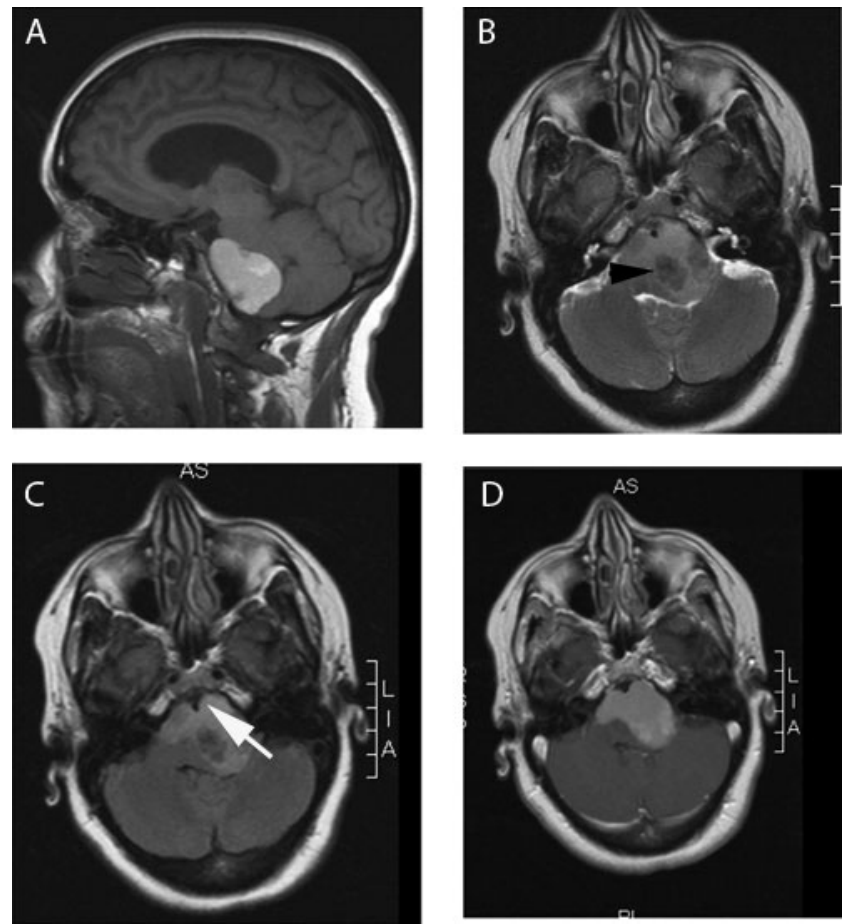

Figure $3 \mathrm{MRl}$ images obtained on admission. (A) Sagittal T1-weighted images show a large mass anterior to the brain stem that is hyperintense to CSF and brain parenchyma. (B) Axial T2-weighted image through the pons shows that the lesion is hypointense to CSF and brain suggesting high protein content. A granuloma on the surface of the brain stem is visible (arrowhead). (C) Precontrast axial T1-weighted image shows the significant compression of the pons and distortion of the fourth ventricle. The basilar artery is pushed far anterior to the brain stem (white arrow). (D) Postcontrast axial T1-weighted images show that there is no significant enhancement of the lesion.

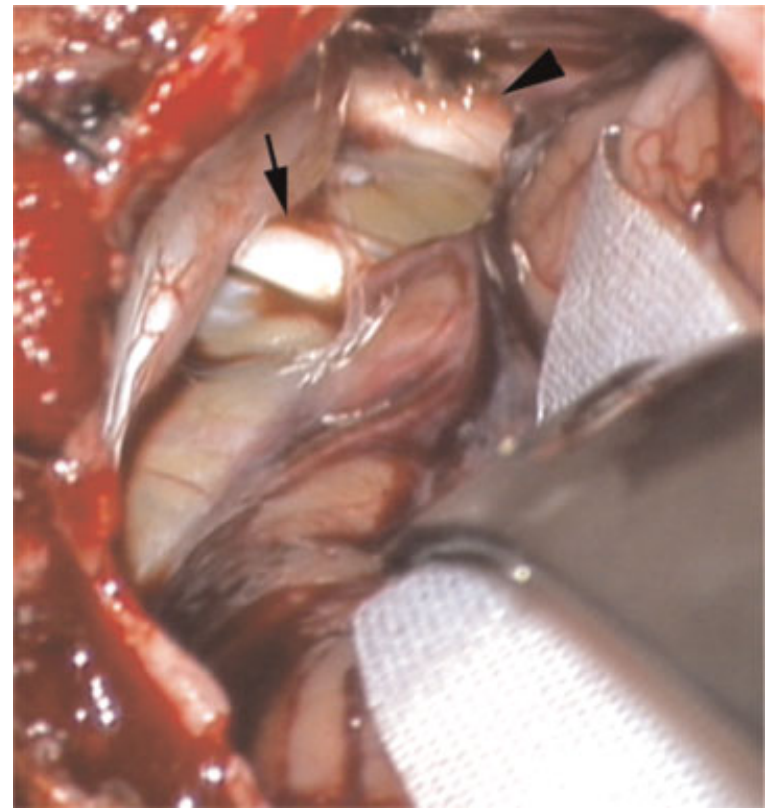

Figure 4 Operative view of the neurenteric cyst. The trigeminal nerve (arrowhead) and the CN VII/NIII nerve (arrow) complex are seen crossing the field. The cyst is filled with viscous, tan fluid. macrophages). The firm deposits on the brain stem represented xanthogranulomatous reaction. Special stains also showed the presence of amyloid deposits within the cyst wall. Examination of the cyst contents revealed histiocytes, cholesterol crystals, and keratin debris.

Postoperatively, the patient had a House-Brackmann Grade III left facial palsy and no other deficits. The facial weakness resolved completely by 12 weeks postoperatively. The patient did not develop any signs or symptoms of aseptic meningitis. Immediate and 3-month delayed postoperative imaging revealed no evidence of residual cyst and re-expansion of the pons with resolution of the distortion of the fourth ventricle and posterior fossa structures (Fig. 7). Imaging of the entire spinal axis at 3 months postoperatively did not reveal any evidence of dissemination.

\section{DISCUSSION}

\section{Pathology}

Neurenteric cysts are lesions filled with fluid, sometimes clear and occasionally cloudy, and lined by a thin 

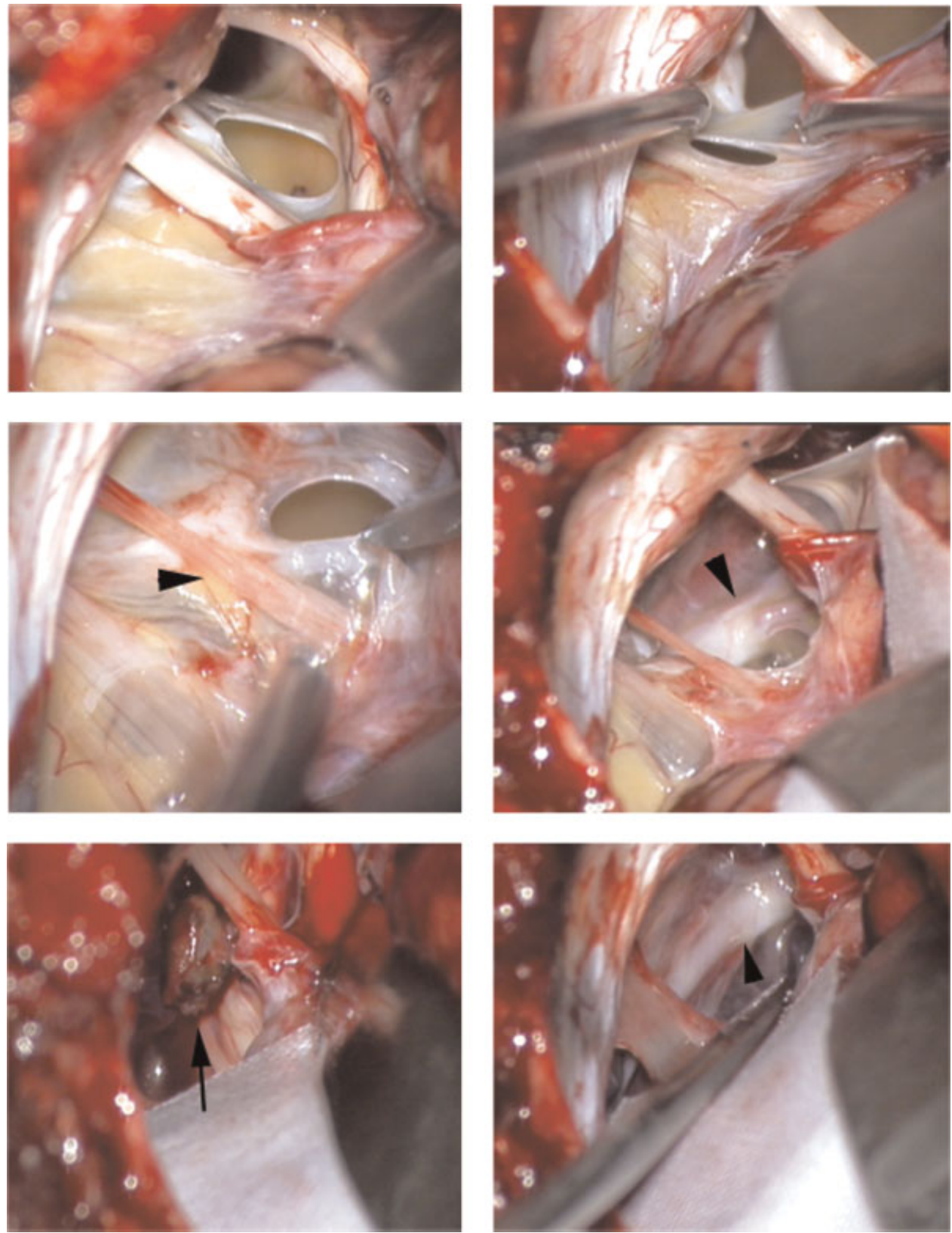

Figure 5 Microsurgical resection of the neurenteric cyst. (Top left) Opening of the cyst wall between the trigeminal nerve and the VIINIII nerve complex. (Top right) Sharply dissecting the cyst wall from the VIINIII nerves. (Middle left) Dissection of the cyst wall from the lower cranial nerves. (Middle right) Partial removal of the cyst contents and the cyst wall reveal the basilar artery (arrowhead). (Lower left) Granuloma on the surface of the pons (arrow). (Lower right) Basilar artery (arrowhead) surrounded by remnants of the cyst wall.

wall of pseudostratified or stratified cuboidal epithelium resting on a basement membrane. ${ }^{2,5,6}$ The cells lining the cyst walls can be ciliated, nonciliated, or mixed. ${ }^{7}$ On gross examination, yellow, white, gray, and red cyst walls have all been noted. The fluid of the cyst, however, is often a clear, yellowish, or brown oily substance. Similar to our case, Ko et al reported finding a yellowish nodule composed of foamy histiocytes and chronic inflammatory cells within a prepontine neurenteric cyst that had undergone xanthomatous changes. ${ }^{8}$ Schwartz et al found xanthogranulomatous change as a marked feature of a cerebellopontine angle neurenteric cyst. ${ }^{9}$

While these cysts are believed to be congenital, confusion surrounds the precise pathogenesis of neurenteric cysts and has led to an assortment of other names (e.g., archenteric cyst, bronchogenic cyst, endodermal cyst). ${ }^{1,3,10-14}$ The name, neurenteric cyst, however, is the most accepted. ${ }^{6}$

Precisely how the endodermal tissue of a neurenteric cyst comes to be found intracranially is still a matter of controversy. The current theories of neurenteric cyst 

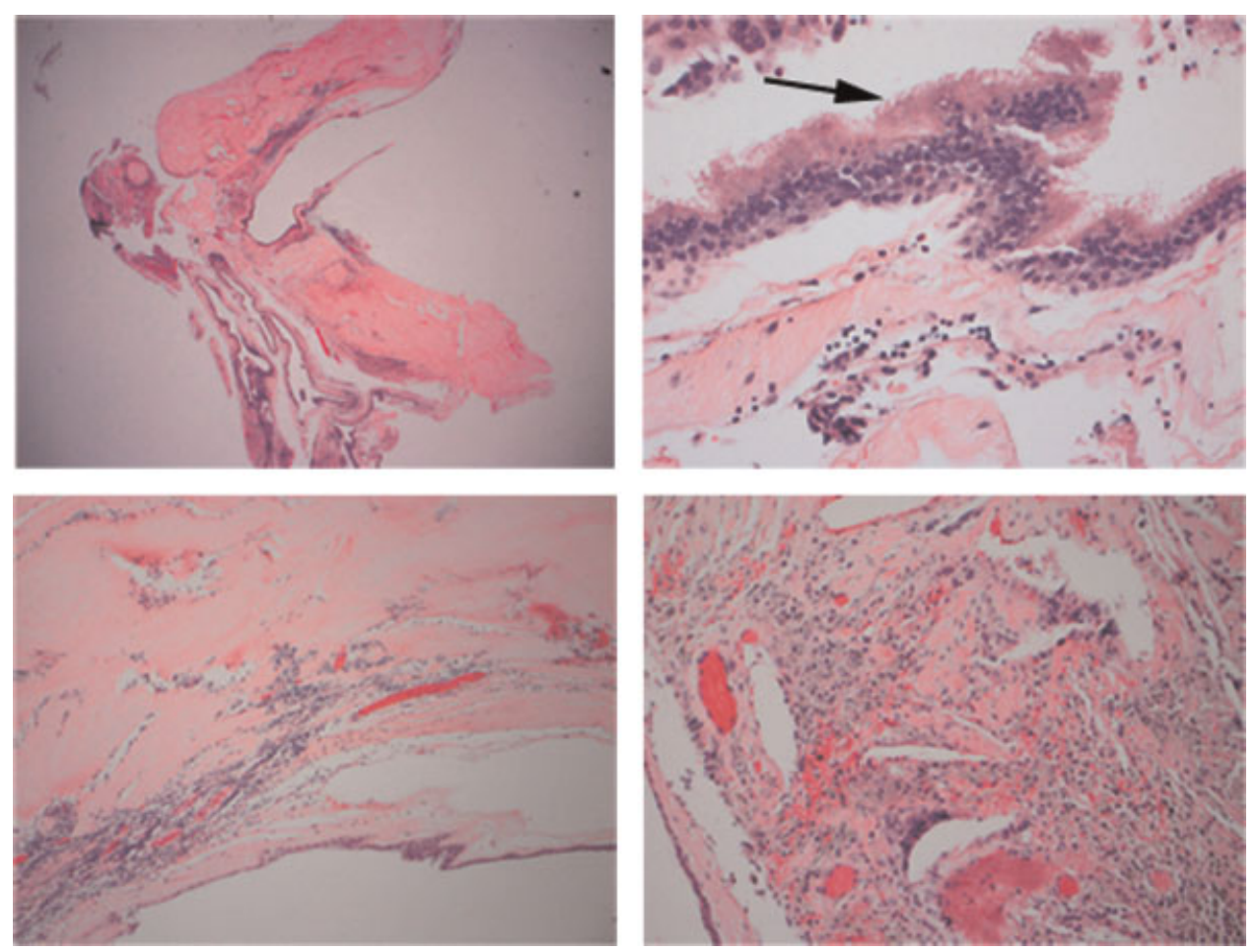

Figure 6 Histopathological examination of neurenteric cyst. (Top left) Low power view of the cyst wall (HE stain). (Top right) High power view of the cyst wall showing pseudostratified ciliated (arrow) epithelium (HE stain). (Bottom left) Part of the cyst wall showing squamous metaplasia with amyloid deposits in the stroma (HE stain). (Bottom right) High power view of the xanthogranulomatous reaction showing multinucleated giant cells, cholesterol clefts, and macrophages (HE stain).

development have been well summarized recently by several authors. ${ }^{1-3,15-17}$ The most commonly held theory is that neurenteric cysts result from an error in the separation of the notochord (the embryonic vertebral column) and the foregut as the neurenteric canal closes during the process of excalation near the third week of gestation. $^{2}$

The epithelium of neurenteric cysts often stains positive for epithelial membrane antigen, cytokeratin, and carcinoembryonic antigen. ${ }^{1}$ Neurenteric cysts test negative for characteristic neuroectodermal markers such as glial fibrillary acidic protein, S100, neuron-specific enolase, and vimentin. ${ }^{18}$ These staining properties and the histopathological findings of respiratory/gastrointestinal epithelia strongly suggest neurenteric cysts are endodermal in origin.

\section{Epidemiology and Clinical Presentation}

While these lesions are being found at higher frequencies in the central nervous system (CNS) due to advances in neuroradiology, neurenteric cysts are most commonly found outside of the CNS, in the posterior mediastinum. ${ }^{18,19}$ They may also be found as a communication between the CNS and mediastinum or the CNS and the abdominal viscera. ${ }^{1,19-21}$ After the posterior mediastinum, the spinal canal is the second most common location for a neurenteric cyst, particularly along the spinal cord's ventral aspect. ${ }^{13}$ Spinal neurenteric cysts may be associated with other anomalies such as dysraphism, hemivertebrae, and VACTERL anomalies. ${ }^{13}$ Neurenteric cysts account for $\sim 0.3$ to $0.5 \%$ of all spinal tumors, half of these are associated with the above-listed deformities. ${ }^{18,22}$ The least common location for a neurenteric cyst is the intracranial compartment. ${ }^{23}$

Intracranial neurenteric cysts are rare, although more than 80 cases of intracranial neurenteric cysts have been reported in the literature. ${ }^{18}$ The most common site is the midline posterior fossa. Unlike spinal neurenteric cysts, these cysts are almost never associated with a bony anomaly of the clivus or skull base. In a review of the literature, Bejjani et al found 46 cases of neurenteric cysts in the posterior fossa, over half of which were located anterior to the brain stem and roughly a fifth of the cases were located within the fourth ventricle. ${ }^{3}$ Others have reported intracranial neurenteric cysts near the lower clivus, ${ }^{18}$ the medulla oblongotta, ${ }^{24}$ the parietal convexity, ${ }^{25}$ within the optic nerve, ${ }^{26}$ and extradurally. ${ }^{7,27}$

There is a bimodal age distribution at presentation for intracranial neurenteric cysts, with a small peak in the first decade and a larger peak in the third and fourth decades. However, cases have been reported in neonates as well as patients in the eighth decade. ${ }^{3,24,28}$ Both female and male predominance have been reported.,29

The most common presenting complaint for intracranial neurenteric cysts is headache. ${ }^{3}$ Gait disturbance, 

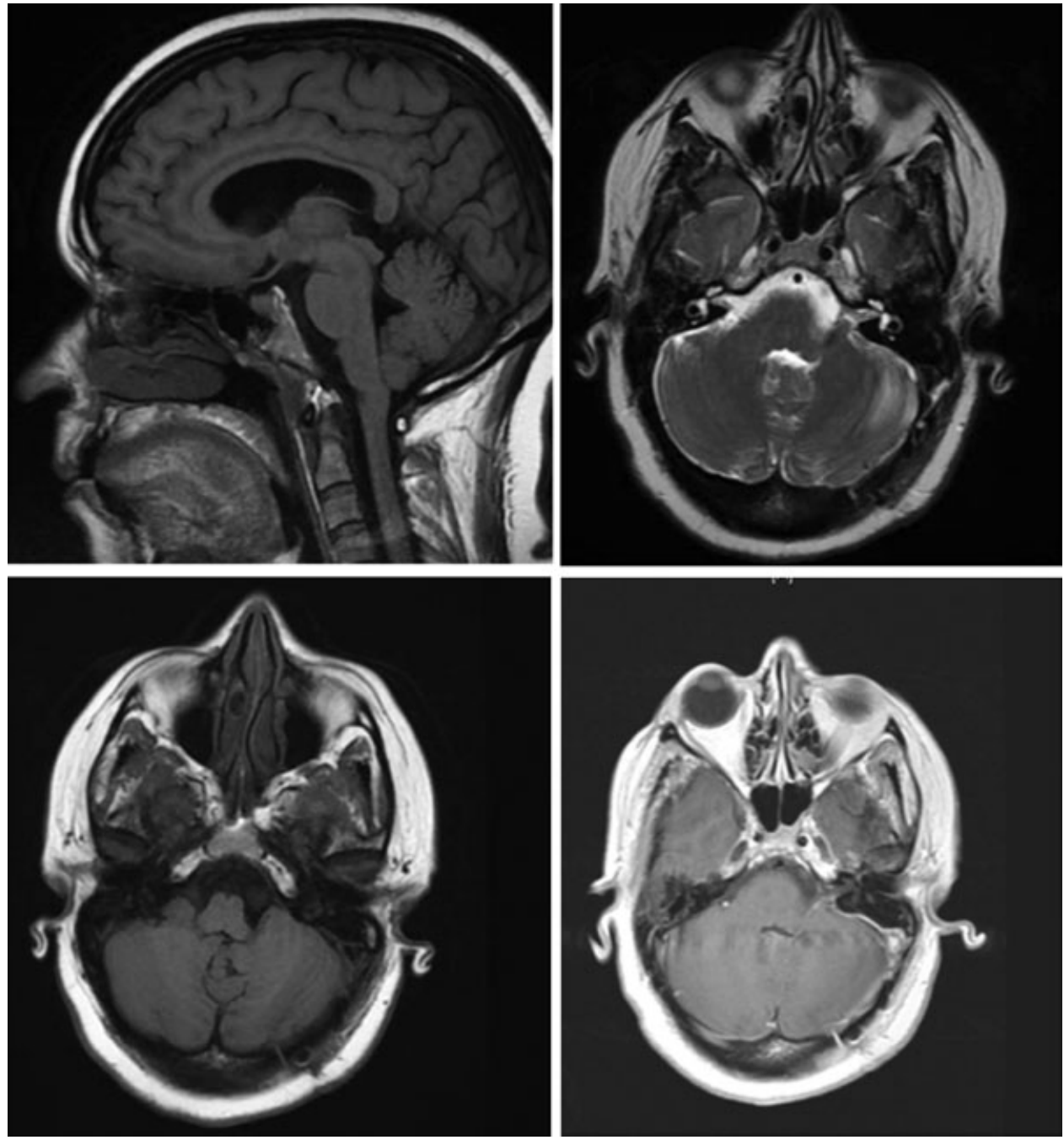

Figure 7 Postoperative MRI after 3 months. (Top left) Sagittal T1 image shows no residual cyst. (Top right) Axial T2 image shows resection of cyst and resolution of the distortion of the brainstem. (Bottom left) Axial T1 image shows normal medulla. (Bottom right) Postcontrast T1-axial image through pons shows no evidence of residual cyst.

extremity weakness, and sensory complaints are reported to be common but less frequent. ${ }^{3}$ Other symptoms have also been reported such as ataxia and memory problems. ${ }^{30,31}$ The symptoms may result from mass effect, irritation of surrounding neural structures, or inflammation. ${ }^{3,18,32}$ Malignant transformation of a neurenteric cyst is believed to be extremely rare. There are six reported cases in the literature. ${ }^{33-35}$

\section{Imaging}

The radiographic appearance of neurenteric cysts can be quite variable. The typical radiological findings have been well summarized by Preece et al. ${ }^{29}$ On CT, neurenteric cysts may appear hypodense (such as CSF) or hyperdense as in our case. The lesion on T1- and T2-weighted MRI may have low, high, or mixed signal intensities. Signal intensity appears to be a function of the cyst-fluid protein content. Highly proteinaceous cysts tend to have T1 signals isointense to hyperintense compared with CSF as in the case presented here. On T2-weighted imaging, neurenteric cysts tend to be hyperintense. Neurenteric cysts do not enhance. Given the variability in their radiological appearance, however, one must also consider other intracranial cystic lesions such as arachnoid cysts, epidermoids, dermoids, Rathke cleft cysts, ependymal cysts, and cystic tumors such as schwannomas. CT can help to exclude arachnoid cysts, for example, if the neurenteric cyst is hyperdense to CSF. Fat suppression MRI can help rule out dermoids. Diffusion imaging can also help rule out dermoid and epidermoid cysts as these cysts often exhibit greater restriction than neurenteric cysts.

\section{Expansion}

Neurenteric cysts are typically thought to be benign and slow growing. ${ }^{6}$ We could find no other case of a rapidly 
expanding neurenteric cyst documented in the literature. Typically, these cysts have been operated on when they become symptomatic, and no serial imaging has been obtained before surgery. Rarely, a neurenteric cyst has been documented as a slowly expanding lesion. Ito et al found a small increase in the size of a cerebellopontine angle cyst by CT, 6 years after the initial examination. ${ }^{36}$ Shakudo et al noted a change in the size of a neurenteric cyst anterior to the brain stem over 33 months. ${ }^{37}$ Although the size change was not as dramatic as in our case, the signal intensity on MRI of the cyst contents changed as well. This change led the authors to conjecture that the balance of secretion and resorption by the cyst led to the increase in size. Finally, Fuse et al found a case of a neurenteric cyst at the craniocervical junction that also enlarged slightly over 4 years. ${ }^{38}$

The most interesting aspect of our case is the rapid increase in size over approximately a year and a half. The cyst that we removed is one of the largest posterior fossa cysts documented to date. Along with the marked increase in dimension, the volume of the cyst increased by $\sim 25$-fold. The mechanism of this marked expansion is unclear. We considered increased secretion, hemorrhage, and inflammation as possible explanations.

Accelerated secretion seems an unlikely cause for growth. The epithelium of the cyst in our case contained very few mucin-secreting cells. At least half of intracranial neurenteric cysts lack a preponderance of goblet cells. ${ }^{29}$ Considering hemorrhage, we saw no evidence of vascularity within this lesion (grossly or microscopically). Indeed, neurenteric cysts are prototypically avascular. However, there was histological evidence of hemorrhage. The acute blood products in the cyst contents were presumably related to surgery, but hemosiderin-laden macrophages were also present in the cyst wall. Inflammation could also be partly responsible for the size increase. We did find many histiocytes and abundant keratinaceous debris in the cyst along with xanthogranulomatous deposits on the brain stem. A cycle of inflammation and hemorrhage followed by more inflammation could be responsible for the increase in cyst size.

\section{Treatment}

Complete removal of a neurenteric cyst is thought to be the ideal treatment as this relieves mass effect, eliminates the risk of recurrence, and reduces the chance of dissemination. Removal of the cyst contents is typically achieved by marsupialization, but complete removal of the cyst wall may be hindered by tight adherence to the surrounding structures. A radical resection of the cyst wall was performed in our case, but adherence to the surface of the brain stem, cranial nerves, and basilar artery branches meant that small remnants of the wall probably remain. Recurrence and craniospinal dissem- ination can occur. ${ }^{35,39,40}$ Because of the possibility of recurrence, dissemination, and malignant transformation, long-term serial imaging is recommended on follow-up. We plan to follow this patient long term with serial MRI.

\section{CONCLUSION}

We demonstrate in this report that neurenteric cysts can expand rapidly even in adult patients. Microsurgical techniques are essential in managing posterior fossa neurenteric cysts as they tend to engulf and adhere to critical neurovascular structures. In addition, close monitoring of even small, asymptomatic neurenteric cysts may be indicated given that they can expand rapidly. Given the low but significant rate of recurrence after surgery, close follow-up is advised.

\section{REFERENCES}

1. Gumerlock MK. Epidermoid, dermoid and neurenteric cysts. In: Winn RH, ed. Youmans Neurological Surgery. 5th ed. Philadelphia, PA: WB Saunders; 2004:1223-1230

2. Tan GS, Hortobágyi T, Al-Sarraj S, Connor SE. Intracranial laterally based supratentorial neurenteric cyst. Br J Radiol 2004;77(923):963-965

3. Bejjani GK, Wright DC, Schessel D, Sekhar LN. Endodermal cysts of the posterior fossa. Report of three cases and review of the literature. J Neurosurg 1998;89(2): 326-335

4. Quiñones-Hinojosa A, Chang EF, Lawton MT. The extended retrosigmoid approach: an alternative to radical cranial base approaches for posterior fossa lesions. Neurosurgery 2006;58(4, Suppl 2):ONS-208-ONS-214; discussion ONS-214

5. Afshar F, Scholtz CL. Enterogenous cyst of the fourth ventricle: case report. J Neurosurg 1981;54(6):836-838

6. Eynon-Lewis NJ, Kitchen N, Scaravilli F, Brookes GB. Neurenteric cyst of the cerebellopontine angle: case report. Neurosurgery 1998;42(3):655-658

7. Basheer N, Kasliwal MK, Suri A, Sharma MC, Arora A, Sharma BS. Lateral extradural, supratentorial neurenteric cyst. J Clin Neurosci 2010;17(5):639-641

8. Ko BS, Jung S, Jung TY, Moon KS, Kim IY, Kang SS. Neurenteric cyst with xanthomatous changes in the prepontine area: unusual radiological findings. J Neurosurg Pediatr 2008;2(5):351-354

9. Schwartz AM, Jensen ME, Saks DA, Ghatak NR. Epithelial cyst in cerebellopontine angle with xanthogranulomatous changes simulating cholesterol granuloma. Surg Neurol 1989; 31(6):454-458

10. Ho LC, Olivi A, Cho CH, Burger PC, Simeone F, Tihan T. Well-differentiated papillary adenocarcinoma arising in a supratentorial enterogenous cyst: case report. Neurosurgery 1998;43(6):1474-1477

11. Batson RA, Scott RM. Neurenteric cysts, teratomatous cysts, teratomas, giant hairy nevi and their associated anomalies. In: Hoffman HJEF, ed. Disorders of the Developing Nervous System: Diagnosis and Treatment. St. Louis: Blackwell Scientific; 1986:733-743 
12. Boto GR, Lobato RD, Ramos A, Ricoy JR, Alén JF, Benito A. Enterogenous cyst of the cisterna magna. Acta Neurochir (Wien) 2000;142(6):715-716

13. Kincaid PK, Stanley P, Kovanlikaya A, Mahour GH, Rowland JM. Coexistent neurenteric cyst and enterogenous cyst. Further support for a common embryologic error. Pediatr Radiol 1999;29(7):539-541

14. Mackenzie IR, Gilbert JJ. Cysts of the neuraxis of endodermal origin. J Neurol Neurosurg Psychiatry 1991; 54(7):572-575

15. Tubbs RS, Salter EG, Oakes WJ. Neurenteric cyst: case report and a review of the potential dysembryology. Clin Anat 2006;19(7):669-672

16. Kulkarni V, Daniel RT, Haran RP. Extradural endodermal cyst of posterior fossa: case report, review of the literature, and embryogenesis. Neurosurgery 2000;47(3):764-767

17. Harris CP, Dias MS, Brockmeyer DL, Townsend JJ, Willis BK, Apfelbaum RI. Neurenteric cysts of the posterior fossa: recognition, management, and embryogenesis. Neurosurgery 1991;29(6):893-897; discussion 897-898

18. Tucker A, Miyake H, Tsuji M, et al. Neurenteric cyst of the lower clivus. Neurosurgery 2010;66(1):E224-E225

19. de Oliveira RS, Cinalli G, Roujeau T, Sainte-Rose C, PierreKahn A, Zerah M. Neurenteric cysts in children: 16 consecutive cases and review of the literature. J Neurosurg 2005;103(6, Suppl):512-523

20. Keating RF, Multani J, Cogan PH. Occult spinal dysraphism and the tethered spinal cord. In: Winn RH, ed. Youmans Neurological Surgery. 5th ed. Philadelphia, PA: WB Saunders; 2004:3257-3288

21. Lee SH, Dante SJ, Simeone FA, Curtis MT. Thoracic neurenteric cyst in an adult: case report. Neurosurgery 1999;45(5):1239-1242; 1242-1243

22. Guilburd JN, Arieh YB, Peyser E. Spinal intradural enterogenous cyst: report of a case. Surg Neurol 1980; 14(5):359-362

23. Dias MS. Enterogenous cyst of the fourth ventricle: case report. Neurosurgery 1998;43(4):984

24. Zalatnai A. Neurenteric cyst of medulla oblongata-a curiosity. Neuropediatrics 1987;18(1):40-41

25. Miyagi AMD, Katayama YMD. Neurenteric cyst arising in the high convexity parietal lesion: case report. Neurosurgery 2007;60(1):E203-E204; discussion E204

26. Scaravilli F, Lidov H, Spalton DJ, Symon L. Neuroenteric cyst of the optic nerve: case report with immunohistochemical study. J Neurol Neurosurg Psychiatry 1992;55(12):11971199
27. Inoue $\mathrm{T}$, Kawahara N, Shibahara J, Masumoto T, Usami K, Kirino T. Extradural neurenteric cyst of the cerebellopontine angle. Case report. J Neurosurg 2004;100(6): 1091-1093

28. Uematsu Y, Rojas-Corona RR, Llena JF, Hirano A. Distribution of epithelial membrane antigen in normal and neoplastic human ependyma. Acta Neuropathol 1989;78(3): 325-328

29. Preece MT, Osborn AG, Chin SS, Smirniotopoulos JG. Intracranial neurenteric cysts: imaging and pathology spectrum. AJNR Am J Neuroradiol 2006;27(6):1211-1216

30. Cheng JS, Cusick JF, Ho KC, Ulmer JL. Lateral supratentorial endodermal cyst: case report and review of literature. Neurosurgery 2002;51(2):493-499; discussion 499

31. Yoshida K, Nakamura S, Tsubokawa T, Sasaki J, Shibuya T. Epithelial cyst of the fourth ventricle. Case report. J Neurosurg 1990;73(6):942-945

32. Adams RD, Wegner W. Congenital cyst of the spinal meninges as cause of intermittent compression of the spinal cord. Arch Neurol Psychiatry 1947;58(1):57-69

33. Dunham CP, Curry B, Hamilton M. Malignant transformation of an intraaxial-supratentorial neurenteric cyst case report and review of the literature. Clin Neuropathol 2009;28(6):460-466

34. Monaco R, Boscaino A, Di Blasi A, et al. Intraepithelial carcinoma arising in an endodermal cyst of the posterior fossa. Neuropathology 2003;23(3):219-224

35. Wang W, Piao YS, Gui QP, Zhang XH, Lu DH. Cerebellopontine angle neurenteric cyst with focal malignant features. Neuropathology 2009;29(1):91-95

36. Ito S, Fujiwara S, Mizoi K, Namiki $T$, Yosimoto $T$. Enterogenous cyst at the cerebellopontine angle: case report. Surg Neurol 1992;37(5):366-370

37. Shakudo M, Inoue Y, Ohata K, Tanaka S. Neurenteric cyst with alteration of signal intensity on follow-up MR images. AJNR Am J Neuroradiol 2001;22(3):496-498

38. Fuse T, Yamada K, Kamiya K, Inagaki H. Neurenteric cyst at the craniovertebral junction: report of two cases. Surg Neurol 1998;50(5):431-436

39. Kimura H, Nagatomi A, Ochi M, Kurisu K. Intracranial neurenteric cyst with recurrence and extensive craniospinal dissemination. Acta Neurochir (Wien) 2006;148(3):347-352; discussion 352

40. Perry A, Scheithauer BW, Zaias BW, Minassian HV. Aggressive enterogenous cyst with extensive craniospinal spread: case report. Neurosurgery 1999;44(2):401-404; discussion 404-405 